\title{
Tribunais nacionais, internacionais e paraestatais: os novos conflitos de jurisdição
}

https://doi.org/10.21814/uminho.ed.30.29

\author{
Solano de Camargo \\ Professor de pós-graduação da Faculdade de Direito da \\ Universidade Anhembi-Morumbi (Brasil)
}

\section{Jurisdição internacional}

A proliferação e a sistemática dos tribunais internacionais requerem uma definição preliminar do conceito de jurisdição internacional.

Como ponto de partida, podemos manter a noção genérica de jurisdição desenvolvida pela teoria do direito. De acordo com esse conceito, de um ponto de vista objetivo, entende-se a função de resolver disputas por meio da interpretação e aplicação da lei em uma determinada lide. Esse aspeto objetivo pressupõe e abrange o procedimento e o próprio julgamento, entendidos como uma série ordenada de atos processuais sucessivos, que desembocam na resolução do litígio.

No direito internacional, a origem da jurisdição internacional se dá por um tratado ou pelo ato de constituição do órgão judicante. Na prática, esses órgãos podem ser chamados tribunais, cortes, comissões ou comitês, enquanto seus membros são nomeados juízes, árbitros ou comissários.

Nesse sentido, é importante resolver agora um problema terminológico que às vezes é levantado pela doutrina sobre a distinção entre cortes e tribunais internacionais. Segundo alguns autores, o termo corte, na prática atual, refere-se a jurisdições internacionais permanentes, enquanto um tribunal internacional teria apenas um caráter provisório, estabelecido para lapso necessário à resolução de uma disputa específica ou a uma série de casos conexos, todos decorrentes da mesma violação ou de uma situação específica. Para efeitos desta pesquisa, respeitadas as designações oficiais de cada jurisdição internacional, usaremos os termos corte e tribunal como sinônimos. Com efeito, para identificar a natureza jurídica de certas organizações, o que realmente interessa não é sua denominação, mas o escopo específico de sua atividade.

Tanto no direito internacional como no direito interno, a função jurisdicional é uma atividade (as mais das vezes) contenciosa, cujo propósito é a solução de uma controvérsia por meio do proferimento de sentenças vinculantes que, por sua vez, declaram direitos, impõem reparação, condenam ou anulam determinados atos. 
Tal definição foi formulada pela primeira vez nas Convenções da Haia de 1899 e 1907 sobre a solução pacífica de disputas internacionais, como já comentado, desde a primeira tentativa de a comunidade internacional organizar uma jurisdição permanente e centralizada, codificando também as regras do julgamento internacional.

A natureza vinculante desse provimento jurisdicional passou a ser o principal elemento de distinção entre esses órgãos e outros meios de solução pacífica de controvérsias internacionais, tais como a negociação, os bons ofícios, a mediação e a conciliação.

E tais idênticos requisitos foram confirmados posteriormente pelos estatutos do Tribunal Permanente de Justiça Internacional (PCIJ) e do Tribunal Internacional de Justiça (CIJ), nos artigos 38, parágrafos 1, 59 e 60. Desde então, tal conceito passou a ser reconhecido pela unanimidade pela doutrina internacionalista.

\section{Breve digressão histórica}

Embora um tribunal internacional permanente de jurisdição geral tenha sido estabelecido apenas no século XX, foi ele precedido por uma longa história de fóruns de arbitragem ad hoc, que serviram como veículos para a resolução de disputas internacionais por terceiros. O Tratado Jay de 1794 marcou o início das modernas arbitragens internacionais, sendo que muitas sentenças arbitrais proferidas nos termos do artigo VII daquele tratado tiveram um papel importante no desenvolvimento das normas de responsabilidade internacional do Estado e prepararam o terreno para o uso de arbitragens internacionais como método adequado de solução de controvérsias.

Entre 1795 e 1922, foram realizadas aproximadamente 350 arbitragens internacionais, muitas das quais envolveram mais de uma sentença. $O$ auge das arbitragens internacionais foi atingido num período de dez anos, entre 1891 e 1900, quando ocorreram 74 procedimentos. Entre 1900 e 1930, foram realizadas 165 arbitragens. Porém, entre 1931 e 1990, as arbitragens declinaram acentuadamente, tendo sido realizadas pouco mais de 50 . No entanto, a partir do final do século passado até a atualidade, em decorrência do fim da Guerra Fria e o advento da globalização econômica, as arbitragens entre Estados voltaram a aumentar consideravelmente.

Na última década, vários Estados indicaram o CPA em contratos-modelo, envolvendo não só os próprios Estados como também entidades e órgãos estatais, em particular aqueles relacionados a recursos naturais e projetos de infraestrutura. Exemplificativamente, nos últimos três anos, agências governamentais na Argentina, Brasil e México publicaram contratos e acordos-modelo relativos à exploração e exploração de petróleo e gás, fornecendo um papel para o CPA em suas cláusulas de solução de controvérsias.

Anteriormente, o Equador já incluía a CPA em seus contratos de serviços de mineração e petróleo, desde 2010. Moçambique e Seychelles também publicaram acordos-modelo em 2016 e 2013, respetivamente, com cláusula compromissória a indicar 
a CPA como tribunal arbitral, mesmo ainda não sendo Estados membros daquela instituição.

O Secretariado do Tratado da Carta de Energia de seus Acordos Intergovernamentais, no modelo padrão para projetos de dutos e eletricidade transfronteiriços, que também preveem a arbitragem da CPA como órgão de resolução de controvérsias.

Aliás, é ainda oportuno lembrar que o Regulamento Sanitário Internacional em vigor, aprovado pela quinquagésima oitava Assembleia da Organização Mundial de Saúde (OMS) em 2005, em vigor desde junho de 2007, também prevê a resolução de controvérsias entre os Estados signatários por meio da CPA, o que significa, na prática, a possibilidade de se discutir o passivo trazido pela pandemia do Covid-19 em face da China.

Embora o estabelecimento do Tribunal de Justiça da América Central (TJAC, 1907), da Corte Permanente de Justiça Internacional (CPJI, 1921 a 1945) e de sua sucessora, a Corte Internacional de Justiça (CIJ, 1945) tenham sido marcos importantes do desenvolvimento da jurisdição internacional, as arbitragens ad hoc e os julgamentos nacionais envolvendo litígios de direito internacional continuam a desempenhar papéis importantes até hoje.

Indiscutivelmente, a atuação dos tribunais internacionais foi catapultada no período subsequente à Segunda Guerra Mundial. A partir de então, a comunidade internacional testemunhou o estabelecimento de vários tribunais permanentes e outros órgãos de solução de controvérsias, surgidos com o propósito de resolver litígios em áreas especializadas do direito internacional. Isso inclui o Tribunal de Justiça da União Europeia (TJUE, 1952); a Corte Europeia de Direitos Humanos (CEDH, 1959); Tribunal Europeu de Energia Nuclear (ENET, 1960); Centro Internacional para Resolução de Disputas sobre Investimentos (ICSID, 1966); o Tribunal BENELUX (1966); a Suprema Corte do Caribe Oriental (CECA, 1967); a Corte Interamericana de Direitos Humanos (CIDH, 1979); o Tribunal de Reivindicações Irã-Estados Unidos (1981), o Tribunal de Justiça da Comunidade Andina (TJCA, 1984); o Tribunal para Conciliação e Arbitragem da Organização para Segurança e Cooperação na Europa (TCACSCE, 1992); o Tribunal da Associação Europeia de Livre Comércio (TEFTA, 1994); o Organismo de Solução de Litígios da Organização Mundial do Comércio e Órgão de Apelação (OMC, 1994) e os sistemas similares do Acordo de Livre Comércio da América do Norte (NAFTA, 1994), do Tribunal de Justiça do Mercado Comum da África Oriental e Austral (TJMCAO, 1998), e do Mercado Comum do Cone Sul (MERCOSUL, 2004); Centro de Arbitragem e Mediação da Organização Mundial da Propriedade Intelectual (OMPI, 1994); o Tribunal Econômico da Comunidade de Estados Independentes (TCEI, 1994); o Tribunal Internacional do Direito do Mar (ITLOS, 1996); o Tribunal Comum de Justiça e Arbitragem da Organização para a Harmonização na África do Direito Comercial (CCJA, 1998); Tribunal de Justiça da África Oriental (EACJ, 2001); o Tribunal Africano de Justiça e Direitos Humanos (TAJDH, 2004); o Tribunal de Justiça do Caribe (TJC, 2005); o Tribunal da União Econômica da Eurásia (TEAEU, 2015). 
As Nações Unidas também fizeram progressos substanciais no desenvolvimento de uma estrutura global de responsabilização por crimes internacionais graves. Foram criados tribunais penais internacionais ad hoc, como o Tribunal de Nuremberg (oficialmente, Tribunal Militar Internacional vs. Hermann Göring et al.,1946-1949); o Tribunal de Tóquio (oficialmente, Tribunal Militar Internacional para o Extremo Oriente, 1946-1948); o Tribunal Penal Internacional para a ex-lugoslávia (1993 a 2017) e o Tribunal Penal Internacional para Ruanda (1995). Todos eles tribunais, por sua vez, abriram caminho para o advento do Tribunal Penal Internacional (TPI, 2002). Além dessas cortes, são dignas de registro Tribunal ad hoc para o Timor-Leste (2000); as Câmaras Extraordinárias dos Tribunais do Camboja (CETC, 2003); o Tribunal Especial do Líbano (TEL, 2007); o Tribunal Especial para Serra Leoa (TESL, 2002); sucedido pelo Tribunal Especial Residual de Serra Leoa (TERSL, 2013); o Mecanismo das Nações Unidas para Tribunais Criminais (MNUTC, 2012); e as Câmaras Extraordinárias da África (CAE, 2013).

Os tribunais administrativos internacionais também desempenham importante papel jurisdicional, tais como os das Nações Unidas (TANU, 1949), da Organização Internacional do Trabalho (TAOIT, 1947), e do Banco Mundial (TABM, 1980), além do Conselho da Organização da Aviação Civil Internacional (COACl, 1944).

Como mencionado, a Convenção Internacional sobre Solução de Controvérsias sobre Investimentos, estabelecida pelo Centro Internacional para Resolução de Disputas sobre Investimentos (ICSID), desempenha uma função importante na resolução de disputas que surgem no contexto do direito internacional privado, assim como a Comissão das Nações Unidas para o Direito Internacional do Comércio (UNCITRAL) também desempenha um importante papel na definição das regras sobre arbitragem comercial.

\section{Etnocentrismo e Direito Internacional}

O pensamento jurídico ocidental, logo após a Segunda Guerra Mundial, enfatizou o relativismo, tanto em termos culturais como ideológicos, nos conceitos, princípios e na definição das instituições judiciárias internacionais.

O conceito central de que o direito e as atitudes sociais de fato, as crenças e os costumes étnico-culturais de qualquer nação ou de minorias não podem ser padronizadas, foi defendido por diversos estudiosos.

Dentro da sociedade internacional, a promulgação de uma norma pode parecer muitas vezes emanada de uma autoridade distante e estrangeira, como ocorria no Império Austro-Húngaro dos Habsburgos que, estabelecidos em Viena, promulgavam normas que deveriam viger nas províncias mais afastadas do interior da Roménia ou da Bulgária.

Na concepção e na construção de um modelo jurídico-institucional para a nova ordem mundial pós-Segunda Guerra, o Departamento de Estado dos EUA e os consultores 
jurídicos reunidos em Yalta e em outras conferências de guerra (sobretudo, na de São Francisco em 1945), redigiram os pilares do que viria a ser a Carta das Nações Unidas. 0 texto, desde o início, projetava sob a comunidade internacional emergente do pós-guerra um modelo de organização baseada fundamentalmente na Constituição e nas instituições políticas dos EUA e na própria experiência histórico-normativa daquele Estado.

A constitucionalização do sistema internacional pós-Segunda Guerra foi inspirada, portanto, a partir de uma visão estadunidense quanto a necessidade de submeter os novos conflitos internacionais a procedimentos racionais e ordenados, conduzidos por órgãos independentes (tribunais internacionais), segregados de outros órgãos com funções legislativas e executivas.

Logo, o novo modelo de tomada de decisões jurisdicionais no âmbito internacional era derivado de uma abordagem inerentemente ocidental para a solução de controvérsias; em outras palavras, era produto de fatores intrínsecos à experiência histórico-jurídica ocidental, ainda não replicados em outras sociedades naquele momento histórico.

Porém, ao longo das últimas décadas, seja em virtude do colonialismo político e econômico, seja pela influência cultural e o intercâmbio científico, sociedades não ocidentais na Ásia e na África acabaram por aceitar e integrar as novas jurisdições internacionais.

Com efeito, a incorporação do modelo constitucional de uma sociedade para outra foi realizada com sucesso pelo Japão em 1946, após a Segunda Guerra. Antes, esse processo já havia ocorrido também na Índia, em 1935, por influência direta do governo colonial do Reino Unido.

\section{Organizações de soft law}

Na prática, os Estados podem optar por estabelecer instituições não baseadas em tratados, também chamadas de organizações de soft law, como era o antigo Acordo Geral sobre Tarifas e Comércio (GATT), a OSCE e o Conselho do Ártico, todas elas aptas a efetuar atividades jurisdicionais atípicas, isto é, não oriundas de um tribunal internacional institucionalizado.

No caso do antigo GATT, seu status jurídico ambíguo era consequência da rejeição pelos Estados Unidos de uma Organização Internacional de Comércio (ITO). O pano de fundo para essa rejeição foi, em parte, o desacordo sobre a conveniência do livre comércio, assim como uma certa desilusão com as Nações Unidas e outras organizações internacionais. O GATT desenvolveu gradualmente uma estrutura institucional na forma de uma secretaria, um conselho e um sistema de solução de controvérsias. Portanto, foi caracterizada como uma organização de facto. 
Quando a Conferência sobre Segurança e Cooperação na Europa (CSCE) estabeleceu a Organização para a Segurança e Cooperação na Europa (OSCE) em 1995, os Estados parte deliberaram que o termo organização não alteraria o status do grupo de cooperação, para o de uma organização institucional (rectius: pessoa jurídica de direito internacional público). Embora vários Estados membros da atual União Europeia tenham proposto à época a celebração de um tratado que desse à CSCE o status de organização internacional com personalidade jurídica, também não houve o apoio dos Estados Unidos para tal desiderato.

Assim, à época, foi adotada uma declaração política, comprometendo-se os Estados participantes a conceder à OSCE capacidade jurídica necessária para a consecução de suas finalidades, e privilégios e imunidades junto aos Estados.

Mas, no caso de organizações de soft law, os Estados membros decidem deliberadamente pela informalidade institucional, o que as distingue das organizações internacionais institucionalizadas.

Embora haja atividades, como dito, legislativas e judicantes, tais organizações de soft law não possuem personalidade jurídica internacional.

\section{Controle judicial das organizações internacionais}

Como corolário lógico do Estado de Direito, o poder público é controlado pelos tribunais. Ao Poder Judiciário é confiada a função jurisdicional do Estado, exercida pelos tribunais e juízes singulares.

Portanto, sua atividade, muito mais que política, tem caráter essencialmente técnico. Mas sua forma varia em diferentes contextos no âmbito interno dos Estados, especialmente se os tribunais têm o poder de controle constitucional da formulação de leis.

O propósito da revisão judicial é tanto um mecanismo de responsabilização, para garantir que o poder executivo cumpra seus deveres constitucionais, quanto para proteger os súditos dos efeitos desses atos.

As decisões proferidas pelas organizações internacionais podem ser tratadas por tribunais internacionais de diferentes maneiras. Em primeiro lugar, a Corte Internacional de Justiça (CIJ) pode ser instada a proferir uma opinião consultiva sobre "qualquer questão legal", no âmbito das Nações Unidas, conforme previsto no artigo 96 da Carta, pela Assembleia Geral, pelo Conselho de Segurança, por outros órgãos da ONU ou mesmo pelas agências especializadas autorizadas pela Assembleia Geral.

Embora o Tribunal tenha expressado sua opinião sobre as decisões da Assembleia Geral e do Conselho de Segurança, também se pronunciou sobre uma decisão da Organização Marítima Internacional (anteriormente, Organização Consultiva Marítima Intergovernamental), assim também como no âmbito da Organização Mundial da Saúde (OMS). 
A validade das decisões proferidas por organizações internacionais contra Estados também pode ser questionada na CIJ, tal como ocorreu no caso Lockerbie, em que a Líbia impugnou as sanções impostas pelo Conselho de Segurança. No caso Bósnia, foi impugnado o embargo de armas adotado pelo Conselho de Segurança, sob a alegação de que tal medida violava o direito de legitima defesa daquele Estado.

\section{Considerações finais}

A pluralidade tem sido uma característica constante na rede institucional formada pelos tribunais internacionais.

E essa pluralidade tem sido administrada não pelo desenho de estruturas hierárquicas, mas, pelo contrário, pela pelo estabelecimento de várias camadas sobrepostas e um sem número de atores, muitas vezes, não estatais.

Nesse contexto, os atores judiciais estão cada vez mais cientes de sua posição em um mundo diversificado de solução de controvérsias, como atores-chave na formação do sistema jurídico internacional. Eles desempenham essa função firmando-se uns com os outros em busca de coerência.

À luz da multiplicação de foros internacionais para a solução de controvérsias, existe uma preocupação generalizada de que os riscos de procedimentos paralelos e decisões conflitantes tenham se tornado mais agudos.

Em última análise, teme-se que isso possa ameaçar a legitimidade da solução de controvérsias.

Esta realidade contemporânea na ordem jurídica internacional é aquela que os sistemas jurídicos nacionais e regionais enfrentam há algum tempo, havendo ferramentas processuais bem desenvolvidas para coordenar a jurisdição nos regimes de direito internacional privado desses sistemas específicos.

Isso sugere que existe uma preocupação primordial em garantir o estado de direito do sistema jurídico internacional, em vez de miná-lo, introduzindo o risco de julgamentos conflitantes, desperdício de recursos e incerteza.

Assim, as sementes foram plantadas para uma coexistência mais ordenada em um mundo de múltiplas cortes e tribunais. Isso também revela várias novas dimensões nos esforços multilaterais entre atores judiciais e estatais. Há uma abordagem gerencial abrangente emergindo.

E por sua própria iniciativa, as cortes e tribunais assumiram a responsabilidade de administrar a pluralidade inerente ao tecido da solução de controvérsias internacionais.

Alguns tribunais se comportam como atores da mudança judicial, favorecendo uma abordagem sistêmica para a solução de controvérsias. 
Sua prática está moldando o surgimento de novos princípios de direito internacional, como o princípio da litispendência ou uma abordagem de conexidade ou de cortesia.

Além disso, ao mesmo tempo em que são atores da mudança judicial, estão contribuindo para o desenvolvimento do direito processual internacional.

Esses vários aspectos são certamente desenvolvimentos recentes dignos de atenção e geralmente contribuem para a promoção do Estado de Direito Internacional de formas inovadoras.

Em certas áreas do direito internacional, os Estados se conscientizaram da necessidade de administrar as consequências da multiplicação de cortes e tribunais.

Dada a natureza transversal dos riscos associados à multiplicação de cortes e tribunais, outras áreas do direito internacional podem aprender e contribuir para essas abordagens gerenciais.

Quanto à contribuição de outras áreas do direito, talvez os conceitos de subsidiariedade ou exclusividade, que encontram aplicação especialmente no direito da UE (entre outras aplicações), ou o princípio da complementaridade, que é uma pedra angular do direito penal internacional, poderia desempenhar um papel na proteção contra incoerência e garantir a legitimidade no contexto de uma ordem jurídica internacional cada vez mais complexa.

Isso quer dizer que, embora certos fios de uma abordagem gerencial já tenham sido, ou estejam sendo, tecidos no tecido plural das cortes e tribunais internacionais, ainda há outros que podem fortalecer essa escolha de tecido no campo do direito internacional privado. 